\title{
A utilização das linguagens artísticas no processo formativo de estudantes de medicina: uma experiência acadêmica
}

\author{
The use of artistic languages in the formative process of medical students: an academic experience
}

El uso de lenguajes artísticos en el proceso formativo de estudiantes de medicina: una experiencia acadêmica

Recebido: 01/02/2022 | Revisado: 05/02/2022 | Aceito: 05/02/2022 | Publicado: 10/02/2022

\author{
Raily de Jesus Oliveira \\ ORCID: https://orcid.org/0000-0002-1442-9380 \\ Universidade Federal da Bahia, Brasil \\ E-mail: raily_oliveira@hotmail.com \\ Ricardo Evangelista Fraga \\ ORCID: https://orcid.org/0000-0001-9345-4869 \\ Universidade Federal da Bahia, Brasil \\ E-mail: ricardoefraga@ hotmail.com
}

\begin{abstract}
Resumo
O presente trabalho tem como objetivo listar as experiências em torno da utilização das linguagens artísticas como ferramenta de aprendizagem das turmas de Medicina em uma Universidade no interior da Bahia, apresentando as contribuições de métodos artísticos no aprendizado dos estudantes de medicina para uma formação que valorize a humanização dos futuros profissionais de saúde. Este caracteriza-se como pesquisa bibliográfica e documental, a partir das referências acerca do tema, planos de aula e documentações responsáveis pelo regimento do curso, além disso, foram correlacionados com a teoria dos tipos de conteúdo de aprendizagem estabelecidos por Zabala (1999). Como resultados, obteve-se uma tabela contendo o semestre, componente curricular, conteúdo, tipo de conteúdo de aprendizagem e linguagem artística utilizada. A partir da análise documental e referencial foi possível observar que os métodos artísticos contribuíram de forma relevante para o ensino dos conteúdos conceituais, procedimentais e atitudinais. Sendo assim, conclui-se que existe um potencial significativo da utilização de linguagens artísticas do processo de formação médica.
\end{abstract}

Palavras-chave: Linguagem artística; Aprendizagem significativa; Arte e educação; Formação médica.

\begin{abstract}
This paper aims to list the experiences regarding the use of the artistic languages as a learning instrument in medical classes at a university in the interior of Bahia, presenting the contributions of artistic methods in the learning of medical students for a training that enhances the humanization of future healthcare practitioners. This study is characterized as bibliographic and documental research, based on references about the theme, teaching plans and the documentation responsible for the course regiment; moreover, they were correlated with the theory of the learning content types established by Zabala (1999). As a result, a table was obtained containing the semester, curricular component, subject, type of teaching content and artistic language used. From the documental and referential analysis it was possible to observe that artistic methods contributed in a relevant way to the teaching of conceptual, procedural and attitudinal content. Therefore, it is concluded that there is a significant potential for the use of artistic languages in the process of medical training.
\end{abstract}

Keywords: Artistic language; Significant learning; Art and education; Medical training.

\section{Resumen}

El presente trabajo tiene como objetivo mencionar experiencias acerca del uso de lenguajes artísticos como herramienta de aprendizaje para las clases de medicina en una Universidad en el interior del estado de Bahia, mostrando las contribuciones de la metodología artística en el aprendizaje de los estudiantes de medicina para una formación que valorice la humanización futuros profesionales de la salud. Esta se caracteriza como investigación bibliográfica y documental a partir de referencias sobre el tema, planificación de las clases y documentación responsable del regimiento del curso, además, se correlacionó con la teoría de los tipos de contenido de aprendizaje establecida por Zabala (1999). Como resultados, se obtuvo una tabla conteniendo el semestre, componente curricular, contenido, tipo de contenido de aprendizaje y lenguaje artístico utilizado. A partir del análisis documental y referencial fue posible observar que los métodos artísticos contribuyeron de forma relevante para enseñar los contenidos conceptuales, procedimientos y actitudes. Por lo tanto, concluimos que existe un potencial significativo en el uso de lenguajes artísticos en el proceso de formación médica.

Palabras clave: Lenguaje artístico; Aprendizaje significativo; Arte y educación; Formación médica. 


\section{Introdução}

O processo de formação dos profissionais médicos sofreu algumas mudanças nos últimos anos, especialmente, a partir de movimentos políticos e educacionais que pautavam a necessidade de reconstrução e aprimoramento do currículo formal de medicina (Brasil, 2014). Durante a década de 90, o Ministério da Educação (MEC) ao avaliar as escolas médicas verificou uma gama de problemas nos currículos, dentre eles o os saberes teórico-práticos dissociados e predomínio de modelo conteudista baseado na transmissão do conhecimento de modo vertical, no qual os discentes possuíam papel passivo no processo de aprendizagem, tal modelo é descrito por Paulo Freire como educação bancária (Freire, 1997; Mourão et al., 2009).

Em contrapartida, é discutido o conceito da Aprendizagem Significativa, que consiste na teoria de que o indivíduo já possui conhecimentos prévios e a aprendizagem ocorre a partir da interação destes com as novas informações adquiridas durante o processo formativo (Ausubel, 2003). Essa teoria é apontada por Melendéz (2012) e Frasson (2016) como uma forma de abordagem propícia para trabalhar o modelo teórico dos Conteúdos de Aprendizagem. Tal modelo está subdividido conteúdos conceituais - o que é preciso "saber", procedimentais - o que é necessário "saber fazer" e atitudinais - conteúdos que formam o "ser", sendo esses conhecimentos existentes na organização cognitiva dos sujeitos possuem um grande desafio no ambiente acadêmico para que sejam trabalhados de forma significativa (Zabala, 1999).

Sendo assim, após décadas de implementação do curso de medicina no Brasil e a revisão quanto as metodologias utilizadas até então, em 2014 foi publicada a mais recente Resolução que institui as Diretrizes Curriculares Nacionais (DCNs) do Curso de Graduação em Medicina (Brasil, 2014). A partir das DCNs, foi criado o Projeto Político Pedagógico (PPP) do curso de Medicina da Universidade Federal da Bahia - Campus Anísio Teixeira (UFBA-CAT), no interior da Bahia, que teve sua primeira turma ingressando em 2016, propõe novos métodos de ensino e aprendizagem, no qual o sujeito obtenha uma formação profissional com uma visão holística e humanística da saúde, contrapondo os modelos de ensino tradicionais, onde o professor é tido como o porta voz do conhecimento e apenas transmite as informações para os alunos de forma vertical. Nesse sentido, o projeto prevê que o aprendizado aconteça de forma que valorize as competências evidenciadas nas DCNs, enaltecendo a aprendizagem mais coletiva e solidária, pois, o conhecimento também se dá na relação com o outro, seja ele colega, professor, profissionais de saúde, usuários do serviço, entre outros (Silva, Scapin, \&Batista, 2011; Casanova, Batista, \& Moreno, 2018). Além disso, o fato da teoria ser abordada distante da prática também foi motivo de críticas pedagógicas, uma vez que submetia ao aluno realidades distantes do que seria visto na prática, ocasionando desperdício de tempo com o que realmente seria importante. Em contraponto, as novas metodologias propiciam a experiência do sujeito durante todos os períodos letivos (Universidade Federal Da Bahia, 2015).

O professor e doutor em Filosofia da Educação, Jorge Larrosa Bondía aborda em suas produções muitas reflexões sobre a experiência, definindo a como "isso que me passa", aquilo que atravessa e produz efeitos para cada um modo único, singular, particular e próprio (Larosa, p.4, 2011), no que se refere a experiência artística e a mesma anteceder a consolidação dos conceitos, possui sua importância na formação de conhecimento, possuindo uma forte influência na valorização do sujeito (Larosa, 2002), concomitante a isso, a arte é uma ferramenta de destaque nesse processo, pois, através de vários meios possibilita um ensino e aprendizado de forma lúdica e significativa (Bertola \& Oliveira, 2010). A experiência é algo que precisa ser valorizado no processo formativo dos profissionais de saúde, pois desperta um olhar diferenciado para o processo do adoecer bem como enaltece um modo de ver e se relacionar no mundo e com o mundo (Larosa, 2002).

Nessa direção, este trabalho tem como objetivo inventariar as experiências em torno da utilização de métodos artísticos no processo de aprendizagem das turmas de Medicina da Universidade Federal da Bahia - Campus Anísio Teixeira, relatando as contribuições de linguagens artísticas no aprendizado dos estudantes de medicina para uma formação que valorize a humanização dos futuros profissionais de saúde. 


\section{Metodologia}

Este trabalho trata-se de um relato de experiência com revisão bibliográfica sobre contribuições de linguagens artísticas no aprendizado dos estudantes de medicina referente ao período do primeiro ao quarto ano, correspondente a etapa que antecede o internato. Foi feita uma análise documental a partir de planos de aula do primeiro ao sétimo semestre de todas as disciplinas cursadas, diários de bordo e anotações feitas pela pesquisadora para identificar os tipos de linguagens artísticas e conteúdos ministrados durante esse tempo. As metodologias de ensino de cunho tradicionais foram excluídas da análise. Os conteúdos identificados como métodos artísticos foram comparados com a documentação responsável pelo regimento do curso, o Projeto Político Pedagógico, a Matriz de Referência do Exame Nacional de Revalidação de Diplomas Médicos Expedidos por Instituição de Educação Superior Estrangeira (Revalida) e correlacionados com a teoria dos tipos de conteúdos de aprendizagem estabelecidos por Zabala (1999).

\section{Resultados e Discussão}

De acordo com o PPP do curso, cada semestre é organizado em núcleos temático que direcionam os docentes acerca das competências e habilidades preconizadas pelas DCNs para o curso de medicina, no entanto, cada componente curricular tem autonomia para eleger sua própria estratégia pedagógica, priorizando a problematização como princípio fundamental e com seus objetivos articulados em prol de um objeto comum: a formação do aprendiz de acordo com as competências, habilidades e valores preconizados no documento (Universidade Federal Da Bahia, 2015).

Durante a presente experiência os docentes utilizaram diversas linguagens artísticas para abordar os seguintes temas: anatomia dos ossos, autocuidado, prescrição ilegível, ética médica, relação médico/paciente, territorialização em ESF, Transtorno do Espectro Autista (TEA), Libras e comunicação de más notícias. As linguagens artísticas utilizadas foram: o método de educação somática - eutonia, cartografia, produção audiovisual, cinema, música e dramatização com o júri simulado e a técnica role play (Tabela 1).

\section{Linguagens artísticas e suas aplicações}

O estudo da anatomia humana é um conteúdo obrigatório da matriz curricular do curso de medicina. Como preconiza o PPP do curso da UFBA-IMS (2015) esse conteúdo já tem início no primeiro semestre, no componente "GIPES - Cultura, arte e natureza: produção e promoção da saúde", no entanto, com a nova proposta de compreender o paciente como um sujeito integral, a eutonia foi o método escolhido pelo mobilizador do componente que também é Eutonista. Nos anos 40, a Eutonia foi criada por Gerda Alexander (1908-1994) na Dinamarca, esse método de Educação Somática convida o ser humano a acessar o estado de autoindependência, maturidade e a busca por um tônus harmonioso juntamente com a consciência profunda do corpo como unidade. Deste modo, essa metodologia convida o sujeito a através de vivências corporais ter uma reaproximação e reapropriação do corpo de acordo com as experiências (Alexander, 1983). As aulas ocorriam dividas em dois momentos: individual, no qual o docente passava as instruções a serem seguidas e indicava os recursos para que os alunos desenvolvessem esse momento de reconhecimento de si mesmo, do seu corpo e promovendo o relaxamento da musculatura para facilitar o processo de explorar as estruturas que seriam estudadas; no segundo momento da aula acontecia a identificação de estruturas anatômicas individual e no colega com ajuda de objetos como bambu, bolinha cravo e saco com sementes (Figura 1). Os assuntos abordados foram anatomia da coluna vertebral, pelve e membros inferiores. Após as aulas, deveria ser realizado um diário de bordo contendo impressões da aula com o apoio do referencial teórico passado pelo docente. 
Tabela 1 - lista de atividades artísticas realizadas do $1^{\circ}$ ao $7^{\circ}$ semestre da formação médica no IMS-CAT-UFBA.

\begin{tabular}{|c|c|c|c|c|}
\hline SEMESTRE & COMPONENTE CURRICULAR & CONTEÚDO & $\begin{array}{l}\text { TIPO DE } \\
\text { CONTEUDO }\end{array}$ & $\begin{array}{l}\text { LINGUAGEM } \\
\text { ARTISTICA } \\
\text { UTILIZADA }\end{array}$ \\
\hline $1^{0}$ & IMSD52 GIPES-Cultura, arte e natureza: produção e promoção da saúde & Anatomia dos ossos & $\begin{array}{l}\text { Conceitual/ } \\
\text { Procedimental/ } \\
\text { Atitudinal }\end{array}$ & Eutonia \\
\hline $1^{\circ}$ & IMSD52 GIPES-Cultura, arte e natureza: produção e promoção da saúde & Autocuidado & Procedimental & Cartografia/ Eutonia \\
\hline $1^{0}$ & IMSD54 GEAC-Elementos estruturantes de uma sociedade saudável & Prescrição ilegivel & Procedimental & $\begin{array}{c}\text { Audiovisual } \\
\text { (produção de video) }\end{array}$ \\
\hline $1^{\circ}$ & IMSD53 GIPES-Docência médica e organização dos serviços de saúde & $\begin{array}{c}\text { Ética Médica } \\
\text { Relação médico/paciente }\end{array}$ & Atitudinal & $\begin{array}{l}\text { Cinema /Júri } \\
\text { Simulado }\end{array}$ \\
\hline $1^{\circ}$ & IMSE11 DCS - A ESF como vetor de reorientação do modelo assistencial & Territorialização em ESF & Conceitual & Cartografia \\
\hline $5^{\circ}$ & IMSD94 GEAC - Direitos humanos e cultura surda: LIBRAS & Libras & Procedimental & Música \\
\hline $5^{\circ}$ & IMSD80 OPS - Tanatologia e morte & $\begin{array}{c}\text { Comunicação de más } \\
\text { noticias }\end{array}$ & $\begin{array}{l}\text { Procedimental/ } \\
\text { Atitudinal }\end{array}$ & Role play \\
\hline $1^{0}-6^{0}$ & Transversal & Saúde mental & $\begin{array}{l}\text { Conceitual / } \\
\text { Procedimental / } \\
\text { Atitudinal }\end{array}$ & Cinema \\
\hline
\end{tabular}

Fonte: Elaborado pelos autores (2021).

Figura 1. Momento individual com objetos utilizados na eutonia (bambu, escovinha e saco de semente).

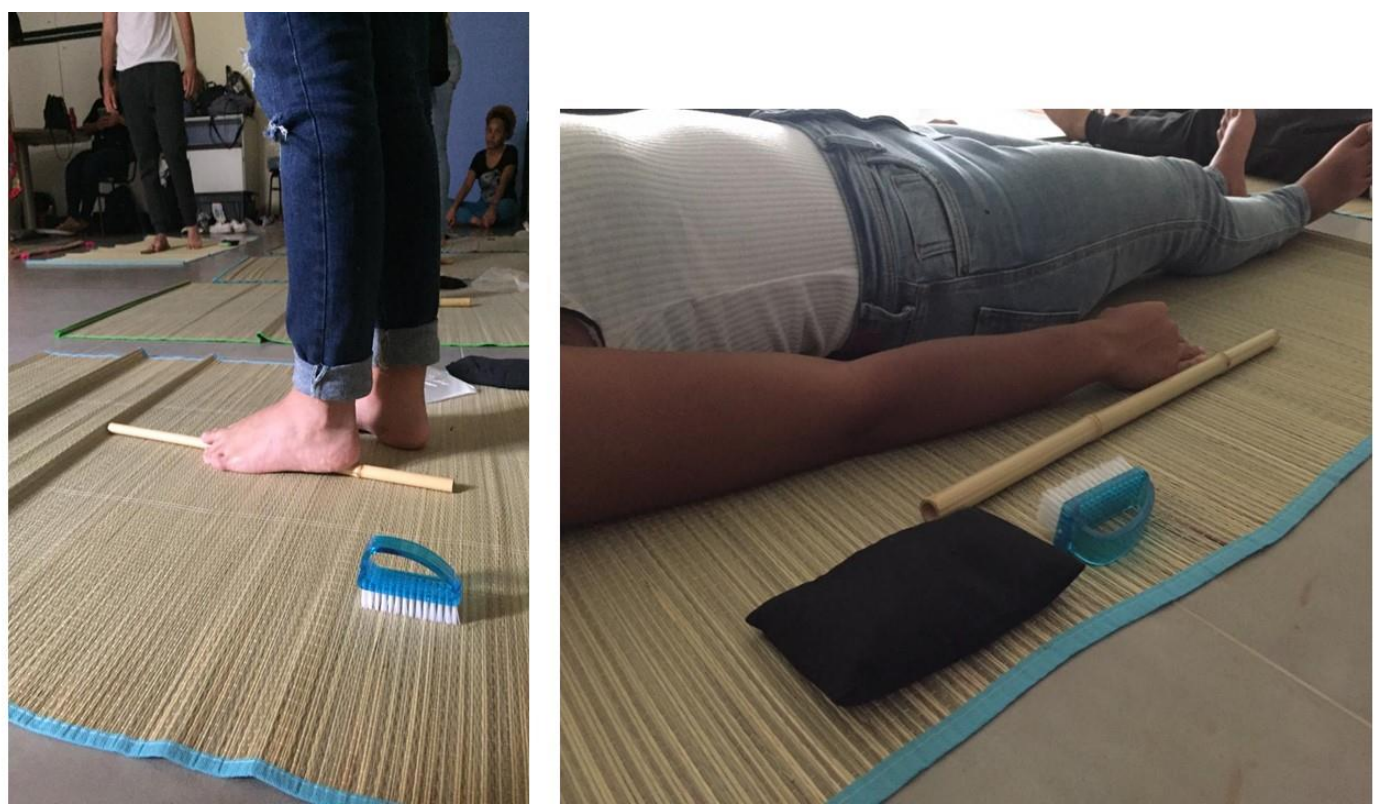

Fonte: Acervo Pessoal (2021).

Bastos (2006) aborda em sua obra o discurso que estudantes de medicina apresentam a respeito da objetificação do corpo de um paciente, partindo do princípio que estudar o cadáver possui uma organização e o considera mais fácil de visualizar estruturas anatômicas, no entanto, esse pensamento anula a subjetividade de um sujeito, cujo um corpo vivo jamais deixará de possuir, ademais, quando chega o momento que a relação médico-paciente-corpo-vivo precisa acontecer se sentem incapazes, pois, se acostumam com o fato de ter algo imóvel que é apenas observado, gerando assim diversos questionamentos, até mesmo éticos. Durante essas aulas, o reconhecimento dos aspectos anatômicos acontecia também com o colega, a partir do reconhecimento no corpo do outro, sendo desafiador para quem tocava e quem era tocado, todavia, para além de uma estrutura 
anatômica, foi um espaço que propiciou trabalhar a relação com o outro uma vez que, esses profissionais da saúde em formação lidam diretamente com indivíduos que carregam suas histórias, crenças e subjetividade diariamente. Tal experiência, é uma forma de despertar o trabalho em grupo, toque sensível, aprender significativamente a lidar com o corpo do outro com respeito e valorizando o corpo vivo com suas particularidades. Deste modo, foi possível trabalhar os três tipos de conteúdo descrito por Zabala (1999), do tipo conceitual ao aprender o nome e localização das estruturas anatômicas, procedimental e atitudinal no que se refere a relação com o corpo do outro, por ser uma anatomia in vivo que será praticada no dia a dia do profissional médico.

Outro método de ensino utilizado ainda no primeiro semestre foi a cartografia. De acordo com a Associação Cartográfica Internacional (2003) a definição de cartografia consiste em uma disciplina que envolve a ciência, arte e a tecnologia de construção e uso de mapas (Meneguette, 2012). Do ponto de vista mais subjetivo, em seu estudo sobre cartografia apresentado no I Seminário Arte e Cidade na Escola de Belas Artes na UFBA em Salvador, Fialho (2006) defende que a cartografia é considerada arte, pois, ambas interpretam, à sua maneira, o espaço, além do mais, a partir das teorias institucionais o ponta pé para consolidação desse conceito foi desde que os mapas conquistaram seu lugar em galerias de arte, museus e exposições. A cartografia foi utilizada como metodologia para trabalhar os temas: autocuidado e territorialização no serviço público de saúde.

A promoção da saúde física e mental em busca do bem-estar como cidadão e médico(a) e o respeito para com seus próprios limites além de estar preconizado no PPP do curso também está presente como conteúdo do Revalida. Ainda no componente "GIPES - Cultura, arte e natureza: produção e promoção da saúde", após o primeiro momento com a eutonia - na qual o aluno foi orientado a levar sua atenção para seu corpo, estruturas e sentimento, ocorreu o segundo momento - onde o discente foi convidado a fazer um mapa do seu corpo (Figura 2) através do decalque da sua própria silhueta em um papel metro e utilizou recortes de revistas e desenhos para incrementar seu produto e com ele representar de maneira livre suas insatisfações, enfermidades ou tudo aquilo que fosse pertinente para si. Após essa reflexão houve o compartilhamento individual das inquietações com o restante da turma (Figura 3. A), finalizando com as orientações do docente para que fosse realizado um exercício de revisão das questões listadas individualmente e a partir daí o discente sugerir o que poderia ser feito para auxiliar na melhoria de cada problema, como estratégia de autocuidado, esse exercício foi conduzido para ser feito em casa (Figura 3. B). Os materiais utilizados foram: papel metro, canetas coloridas, revistas, tesoura e cola.

Trabalhar o autocuidado durante a graduação tem ganhado evidência, pois, é algo que influencia diretamente no processo de aprendizagem do indivíduo e consequentemente sua conduta no ambiente de atuação profissional, além de ser um tema preconizado pelas DCN's do curso de medicina (Rotenstein, et al., 2016; Paro, et al., 2019). Em vista disso, a universidade também faz parte desse processo por ter o poder de influenciar na qualidade de vida dos estudantes (Hwang, et al., 2017). A atividade realizada para abordar esse tema foi algo que despertou nos discentes um olhar sensível para a saúde física e mental naquele momento, principalmente um olhar direcionado para o corpo em si, que muitas vezes é deixado de lado para dar conta dos afazeres da própria faculdade, sendo negligenciados alimentação, lazer, atividade física e até mesmo uma boa noite de sono. Poder vivenciar momentos como esse no próprio curso, proporciona uma atenção especial para o tema e a reflexão de que é preciso se cuidar para garantir que o cuidado também chegue para o outro. Portanto, através desses instrumentos artísticos utilizados para abordar o autocuidado foi possível trabalhar o tipo de conteúdo procedimental. 
Figura 2. Cartografia de si. Desenho realizado buscando descrever pontos que necessitam de cuidado e/ou apresentar questões subjetivas e simbólicas do corpo de cada estudante.

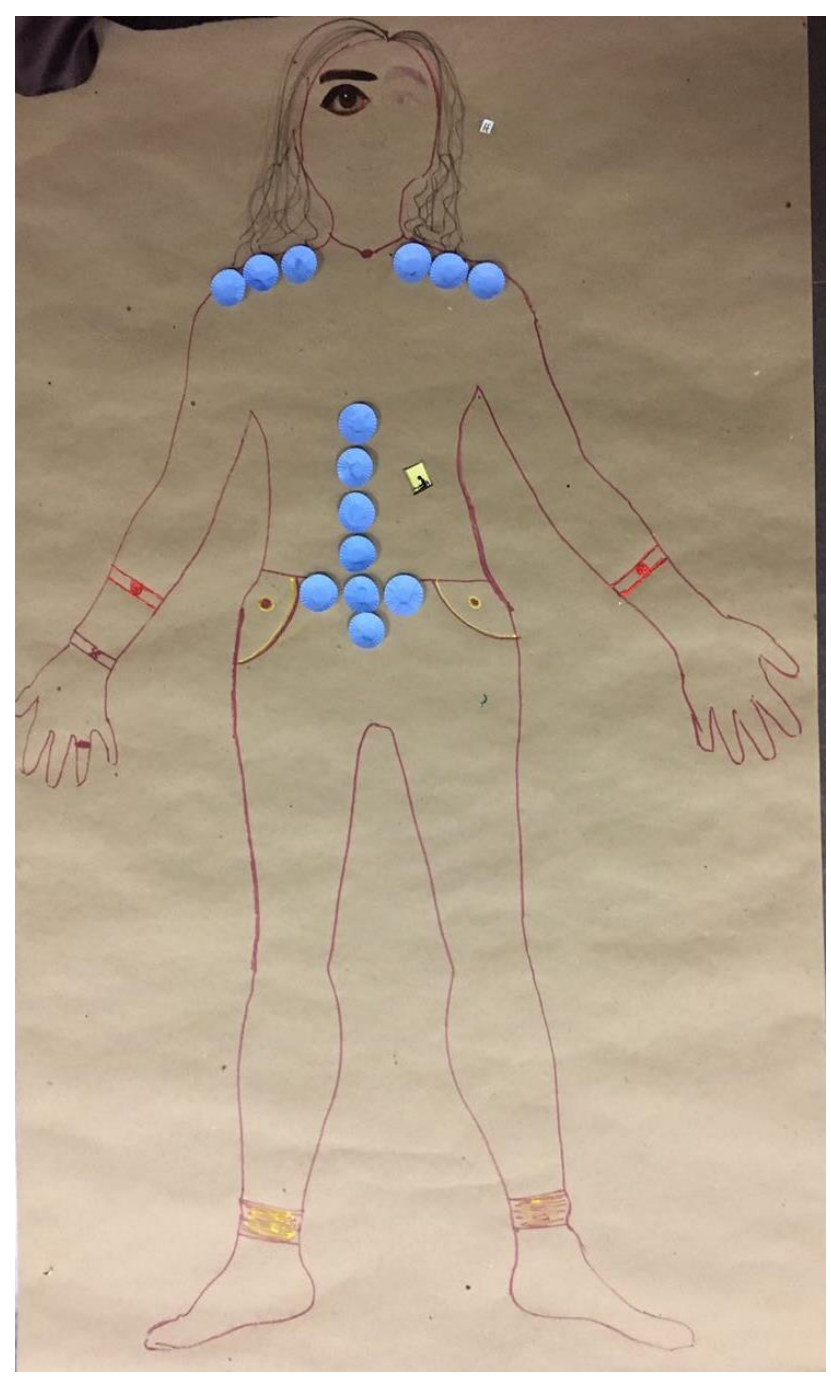

Fonte: Acervo Pessoal (2021).

No componente "DCS - A ESF como vetor de reorientação do modelo assistencial" a cartografia foi utilizada para trabalhar em aspectos preconizados no projeto pedagógico do curso, pois, no âmbito da Medicina Social, alguns dos objetivos são preparar o aluno para intervir de modo reflexivo nas políticas de saúde, organizações dos serviços, atuar na construção e desenvolvimento do sistema público de saúde, entre outros. A atividade aconteceu a partir da visita de diferentes grupos em diferentes microáreas de Estratégias de Saúde da Família (ESF) da cidade de Vitória da Conquista - Ba, antes da visita foi enviado um referencial teórico para auxiliar na visita ao campo, entrevistas com profissionais da ESF e ao final foi realizado um relatório da territorialização. A partir dessas informações contidas no relatório, cada grupo foi instruído a seguir algumas instruções, que resultou em: $1^{\circ}$ momento - cada equipe construiu uma representação gráfica da microárea com o material disponível, que poderia conter aspectos geográficos, condições de vida, equipamentos de saúde, assistência social, educação, entre outros aspectos que a equipe julgou relevante (Figura 4); $2^{\circ}$ momento - as equipes fizeram socialização dos produtos, onde cada grupo visitou o outro para conhecer as respectivas produções; e $3^{\circ}$ momento - após conhecerem o trabalho das demais equipes, os alunos compartilharam suas impressões e descobertas com o grupo de origem e então foi disponibilizado um tempo a mais para revisar seu trabalho e realizar uma crítica do mesmo, enfatizando os pontos fortes e os que poderiam melhorar. Os recursos utilizados foram: isopor, palito de sorvete, garrafas pet, tampas, caixinhas de papelão, tinta plástica, 
papel crepom, cartolina, massa de modelar, tesoura, estilete, cola, pincel e outro que o grupo optasse por levar.

A linguagem cartográfica possibilitou aos alunos manifestarem suas considerações sobre cada território explorado por meio de signos, que são sinais ali designados para representar a realidade mapeada a partir da interpretação e vivência de cada grupo (Silveira \& Jayme, 2014). Para além do espaço geográfico, foi possível trabalhar com uma perspectiva acerca dos diversos elementos que moldam a vida e a saúde da população de uma localidade e sobre como impactam direta e indiretamente no processo saúde-doença da comunidade. Visualizar essas questões no produto cartográfico torna o aprendizado ainda mais significativo para o estudante, pois possibilita a visualização das necessidades e demandas de saúde naquela microárea, desenvolvendo o pensamento crítico-reflexivo para esse desafio que é o Sistema Único de Saúde (SUS) (Franco \& Merhy, 2012). Sendo assim, conteúdos do tipo conceituais e procedimentais foram apresentados através dessa dinâmica.

Figura 3. Figura 3. A. Diário de bordo realizado após atividade em sala para descrever os pontos de autocuidado de si. B.

Diário de bordo realizado em casa com estratégias de melhoria para os pontos descrito em sala (figura 3. a).

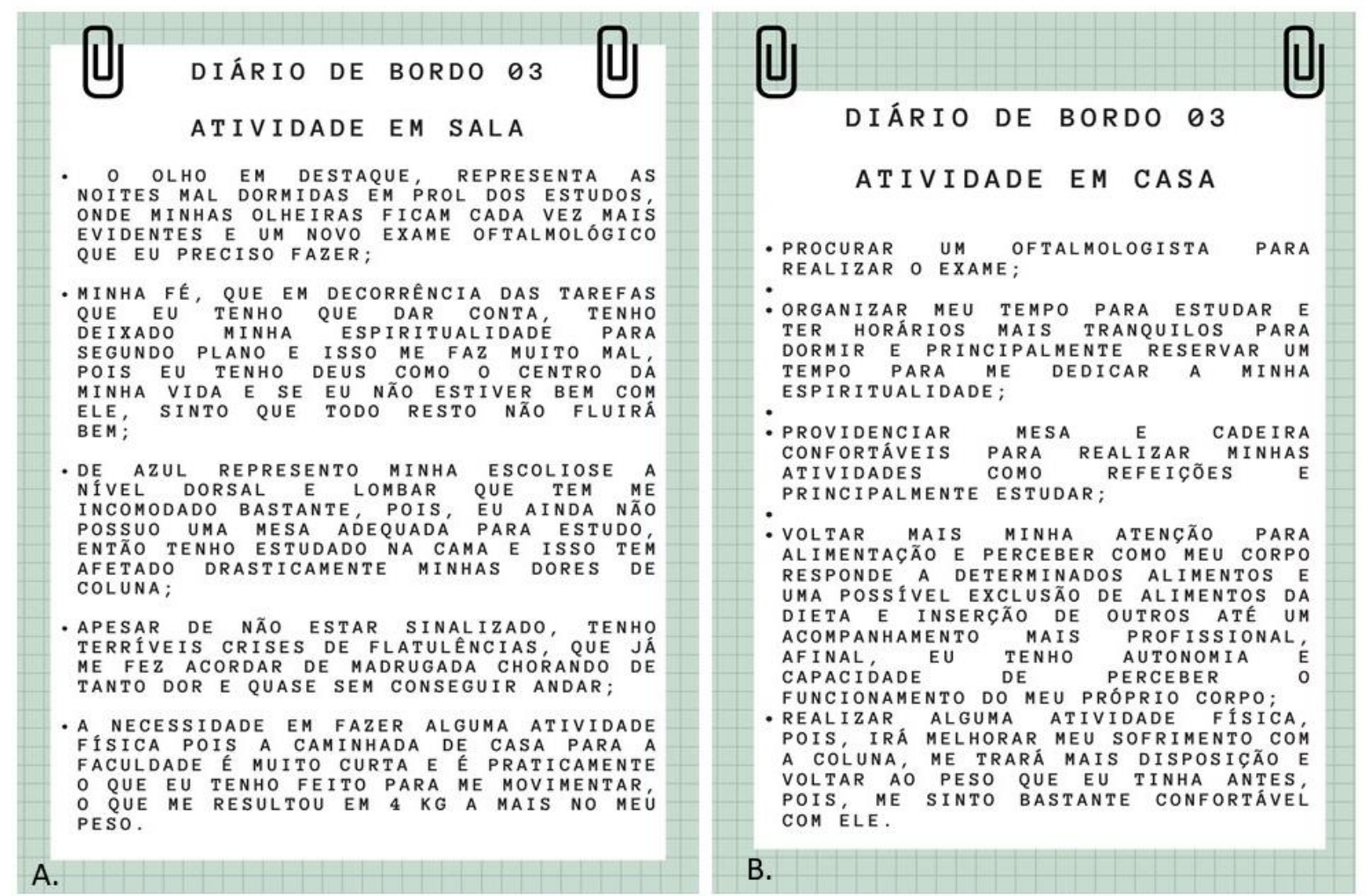

Fonte: Acervo Pessoal (2021).

Outro instrumento utilizado para trabalhar conteúdos ainda no primeiro semestre foi a dramatização, que pode ser caracterizada como uma representação teatral, que proporciona ao sujeito o despertar de muitas habilidades, sendo elas motoras, cognitivas, linguísticas e sociais, possibilitando uma experiência significante na construção da sua individualidade e subjetividade dentro do ambiente acadêmico e fora dele (Lorenz et al., 2004; Silva et al., 2019). 
Figura 4. Cartografia de uma microárea realizada no componente "DCS - A ESF como vetor de reorientação do modelo assistencial”.

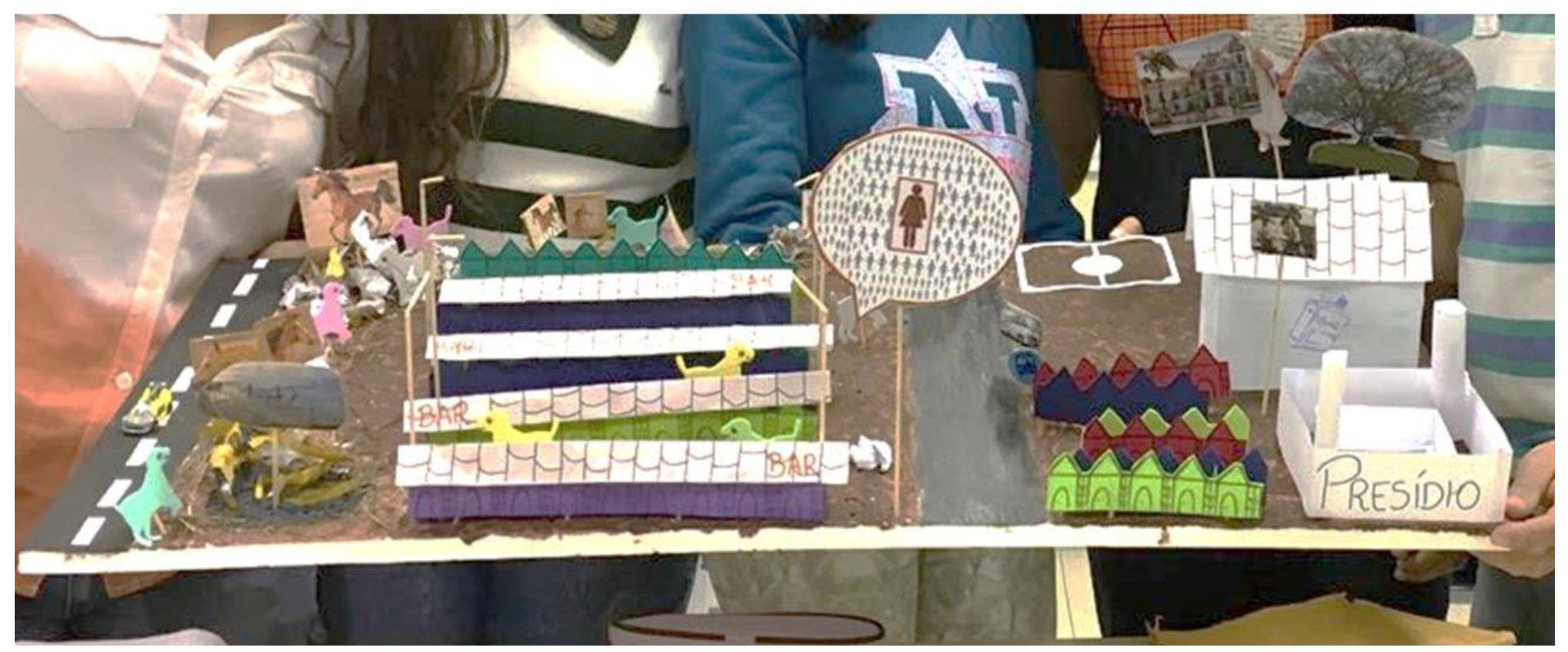

Fonte: Acervo Pessoal (2021).

Na esfera da Bioética, o PPP do curso recomenda alguns pontos que são considerados indispensáveis ao médico em seu exercício da profissão, como apresentar postura ética, compreender e respeitar o código de Ética Médica, corroborando com esses temas, o Revalida preconiza a abordagem de aspectos éticos e relação médico-paciente. Para suscitar um debate nessa área, cujo tema proposto foi "Os limites da relação médico-paciente" no componente "GIPES - Docência médica e organização dos serviços de saúde”, foi utilizado a técnica Júri Simulado que possui em sua essência a prática da dramatização, para discutir o caso de uma médica que se apaixona pelo paciente com transtorno bipolar. Esse caso foi retirado do filme Mr. Jones (1993). Para realização da metodologia, a turma foi dividida entre acusação, defesa e suas respectivas testemunhas, um professor convidado como juiz e outro ocupando o cargo de promotor do caso.

Apesar de existir um documento que descreva como o profissional médico deve agir diante dos seus pacientes (Conselho Federal De Medicina, 2018), quando esses profissionais são colocados na prática do dia a dia, é preciso mais do que teoria para saber lidar com os dilemas que muitas vezes são confrontados. O júri simulado é uma ferramenta de ensino que promove aos discentes vivenciar uma realidade através da interpretação de papéis que existem na vida cotidiana, possibilitando que o futuro médico consiga experimentar, ainda que de forma simulada, situações que podem lhe acometer em um futuro não tão distante (Filho, 2003). Essa metodologia fomenta nos alunos o pensamento crítico e reflexivo seja qual for o tema abordado, além de promover um ambiente mais dinâmico para o aprendizado (Mongelli et al., 2021). Ademais, é possível afirmar que conteúdos do tipo atitudinal foram bastante explorados com essa dinâmica.

Ainda na área da Ética Médica, o profissional possui diversas atribuições que lhe são vedadas durante o exercício da profissão, dentre elas "Art. 11. Receitar, atestar ou emitir laudos de forma secreta ou ilegível, sem a devida identificação de seu número de registro no Conselho Regional de Medicina da sua jurisdição, bem como assinar em branco folhas de receituários, atestados, laudos ou quaisquer outros documentos médicos." (Conselho Federal De Medicina, 2018). Tendo em vista a importância em abordar esses tópicos ao longo da formação acadêmica, durante o componente "GEAC- Elementos estruturantes de uma sociedade saudável" foi realizada uma atividade de Produção Audiovisual (PAV), onde a turma foi dividida em grupos e cada um ficou responsável por fazer uma produção de audiovisual do tipo curta metragem, de caráter informativo sobre aspectos da farmacologia no exercício da medicina, dentre eles os legais e éticos acerca da prescrição 
ilegível.

Machado et. al. (2013) aponta em seu estudo sobre produção videográfica, que a produção de Audiovisual além de demonstrar-se como uma inovação metodológica, possui um papel significativo no que se refere a Arte, através do seu potencial estético em evidenciar o conhecimento que foi adquirido e transformado naquele determinado produto. O vídeo foi realizado a partir de histórias reais sobre consequências de uma prescrição ilegível, nas quais os discentes também utilizaram da dramatização para enriquecer o conteúdo produzido. Outro ponto a ser destacado é a oportunidade de trabalhar em equipe já no primeiro período, fomentando a responsabilidade e aproximando a comunicação, arte, cultura e saúde através dessa linguagem artística que tem sido mencionada com efeitos positivos na docência (Machado et al., 2013; Silva et al., 2020). Assim, os conteúdos atitudinal e procedimental foram explorados a partir dessa metodologia.

De acordo com o Revalida, estar habilitado para realização da comunicação de más notícias e de perdas a pacientes e familiares é algo que o médico precisa estar durante o exercício da sua profissão. Deste modo, no componente "OPS Tanatologia e morte" situado no quinto semestre, foi realizado um Role-Play para trabalhar o tema Comunicação de más notícias. Role-Play é uma técnica que também lança mão da dramatização através de simulação de possíveis situações, objetivando desenvolver prática e habilidades sociais, na qual os participantes são instruídos a desenvolver essa metodologia a partir de situações reais do cotidiano de acordo com a temática aplicada (Knapp \& Beck, 2008; Fiuza \& Lhullier, 2018). Lidar adequadamente com a morte e o sofrimento faz parte do planejamento das diretrizes curriculares do PPP, para tanto, a atividade realizada foi constituída por duas fases: "escura" - o aluno não possuía acesso ao estudo prévio e a fase "clara" onde o acesso ao conteúdo era necessário. Na primeira fase foi construído um ambiente de atendimento ambulatorial cujo motivo da consulta seria informar um diagnóstico de doença em estágio terminal, o grupo se dividiu através de um sorteio realizado no momento da aula e os papéis foram designados para cada um, sendo eles: paciente, acompanhante, médico e observador da cena. Após a realização da técnica, o grupo se reuniu para discutir como foi a experiência, sensações e pontos que seriam abordados na próxima aula. Como principal referência para o tema, o docente sugeriu o protocolo SPIKES (Cruz \& Riera, 2016). Na semana seguinte foi realizado um novo sorteio entre o grupo para a comunicação do óbito de um jovem para a sua família, sendo os personagens: pais do paciente, namorada, médico e equipe de saúde. Para finalizar o momento, a discussão foi retomada, no entanto com todos do grupo possuindo o estudo prévio.

A técnica de simulação é um recurso que possibilita ao aluno vivenciar a rotina médica através da abordagem de situações existentes no exercício da profissão, ainda no ambiente acadêmico. Deste modo, os discentes têm a oportunidade de discutir e refletir sobre temáticas de uma forma teatralizada, permitindo um pouco de realidade para situações que serão constantes no seu dia a dia como médicos. O tema em questão, por ser algo delicado e apesar de ter como ferramenta teórica o protocolo SPIKES, que orienta como deve ser feita a comunicação de más notícias, foi algo bem desafiador para todos que participaram da dramatização, no entanto, esses momentos são importantes para quando o aluno se depare com situações como essa, já tenha uma postura mais sensível à frente dessas problemáticas (Lino et al., 2011). A partir dessa estratégia, o conteúdo do tipo atitudinal e procedimental obtiveram mais ênfase nesse processo de aprendizagem.

O componente "GEAC - Direitos humanos e cultura surda: LIBRAS" possui uma proposta que abarca habilidades médicas e conhecimento funcional da Língua Brasileira de Sinais (LIBRAS), considerada como a segunda língua oficial do Brasil, sua modalidade é visual-motora e possui uma estrutura gramatical própria que propicia a comunicação entre às pessoas surdas e com os ouvintes (Brasil, 2002). No que se refere ao cenário da saúde, os surdos ainda possuem bastante dificuldade de acesso às informações e aos serviços, além do quesito escolaridade ser na maioria das vezes inexistente, existe também a falta de profissionais que dominem a língua (Silva, et al., 2021). O fato de existir um componente no curso que seja voltado integralmente para o ensino da LIBRAS não irá solucionar todos os problemas de acesso para essas pessoas, no entanto, esse contato com a língua já promove aos alunos conhecimentos acerca das dificuldades encontradas e podem suscitar o interesse 
em se aprofundar mais sobre as técnicas, já que a qualquer momento é possível atender um paciente surdo em qualquer serviço de saúde.

Para melhor trabalhar os conteúdos neste componente, a música se mostrou uma importante aliada, sendo uma arte que faz parte da vida do ser humano de várias formas, seja em um momento de extrema felicidade ou até mesmo que traga lembranças ruins (Hatem et al., 2006). Quando possui uma letra, essa obra de arte pode ser utilizada para aprender de forma mais didática e significativa os sinais da Libras. Além do mais, essa linguagem artística é capaz de despertar o interesse do aprendiz em conhecer essa segunda língua por sua diversão e ludicidade que promove prazer ao mesmo tempo que uma aprendizagem significativa, fazendo com o que o aluno ouvinte utilize recursos como memória, atenção, concentração, sensibilidade, respeito com o próximo e trabalhe uma grande necessidade social que é a inclusão, a partir desse conhecimento dos ouvintes e assim poder se comunicar com os surdos de maneira eficiente (Loureiro, 2001; Bréscia, 2003; Ferreira \& Queiroz, 2021). A partir dessa abordagem foi possível trabalhar majoritariamente o conteúdo do tipo procedimental.

Ainda sobre o curso, vale a pena enaltecer o fato da saúde mental ser um conteúdo transversal, perpassando por todos os semestres que antecedem o internato e presente no documento Revalida como conteúdos indispensáveis na prática médica. O cinema foi uma das metodologias mais utilizadas durante esse processo de ensino, sendo uma ferramenta geradora de muitas reflexões, discussões e bons resultados. Sendo assim, é possível listar alguns filmes utilizados: Mr. Jones (1993), Hipócrates (2014), Divertidamente (2015), Um estranho no ninho (1975), Amnésia (2000), Temple Grandin (2010) e Estamira (2004).

Pensar o ensino da saúde mental de forma mais lúdica e interativa tem sido possível e colocado em prática a partir das produções de cinema, ao dar espaço e mostrar diversos transtornos mentais e os desafios de tais psicopatologias em suas telas (Honorato et al., 2021). A utilização de filmes foi aceita pela turma desde o primeiro semestre do curso, sempre de maneira positiva. Foram trabalhados temas como: Esquizofrenia, Transtorno de Asperger, Transtorno maníaco-depressivo e outras questões que permeiam a saúde mental.

Proporcionar uma experiência educativa significativa no ambiente acadêmico tem sido um desafio para muitos docentes independente da área de ensino (Coutinho \& Lisbôa, 2011). No entanto, utilizar filmes como ferramenta pedagógica para promover uma experiência didática relevante, tem sido eficaz, pois, através da dramatização, o estudante pode desfrutar de situações que existem na prática médica mas que ainda não está exposto e assim, refletir a respeito dos cenários que lhe são apresentado e influenciando no desenvolvimento de atitudes e posturas a respeito dos temas abordados através dessa arte que é o cinema (Picanço, et al., 2019).

Em seu artigo que discute o uso do Cinema na Educação Médica, Blasco (2010) aborda o papel que a arte possui no processo de ensino-aprendizagem dos acadêmicos de medicina no que se refere a temas voltados para Humanização da Medicina como o desafio em cuidado do paciente, lidar com a família do paciente, entre outros assuntos. $\mathrm{O}$ autor defende que o cinema é uma linguagem artística e didática que torna o aprendizado dos discentes mais palpável, estimulando a reflexão no que se refere a regras de condutas, raciocínio clínico e integração de conhecimentos já adquiridos e que o cinema permite que sejam postos em prática. Em outro estudo, Bhagar (2005) aborda que essa arte tem se mostrado proveitosa no estudo de transtornos mentais, sendo bastante aceita pelos alunos. Durante a experiência no curso, foi possível experimentar esses caminhos que a dramatização no audiovisual fornece, onde foi trabalhados conteúdos do tipo conceitual, procedimental e sobretudo atitudinal.

\section{Considerações Finais}

Pensar o curso de medicina com as novas metodologias ativas ainda tem sido bastante desafiador, seja para o corpo docente como para o corpo discente. No entanto, através do exposto é possível observar que as linguagens artísticas possuem um potencial significativo para contribuir com a formação médica, possibilitando novas discussões e vivências que auxilia no 
processo de ensino e aprendizagem significativa, permitindo a abordagem de conteúdos nas três dimensões da produção do conhecimento - conceituais, procedimentais e atitudinais.

Trabalhos futuros que contemplem as descrições dos objetivos, conteúdos abordados, caminhos metodológicos e procedimentos avaliativos de cada experiência aqui descrita podem contribuir com a utilização das Artes na formação médica em outras instituições de ensino. Além disso, o presente estudo, atua para incentivar os docentes a buscarem formação complementar para a implementação de metodologias que utilizem das Artes em seus componentes curriculares, oportunizando um aprendizado mais significativo para o corpo discente. Neste sentido, é sugerido também que, nos encontros pedagógicos para formação continuada do corpo docente, a temática aqui apresentada esteja presente.

\section{Referências}

Aguilar-da-Silva, R. H., Scapin, L. T., \& Batista, N. a. (2011). Avaliação da formação interprofissional no ensino superior em saúde: aspectos da colaboração e do trabalho em equipe. Revista de Avaliação da Educação Superior, 16 (1), 167-184.

Alexander, G. (1983). Eutonia - um caminho para a percepção corporal.: Martins Fontes.

Ausubel, D. P. (2003). Aquisição e retenção de conhecimentos: uma perspectiva cognitiva. Paralelo.

Barbosa, M. R., Mena Matos, P., \& Costa, M. E. (2011). Um olhar sobre o corpo: ontem e hoje. Psicologia \& Sociedade, 23(1), $24-34$.

Bastos, L. A. (2006). Corpo e Subjetividade na Medicina: impasses e paradoxos. UFRJ.

Bertola, L., \& Oliveira, G. (2010). A arte como ferramenta didática no ensino superior. Realize.

Bhagar, H. (2005). Should cinema be used for medical student education in psychiatry? Medical Education, 39(9), 972-973.

Biasco, P. G., Gallian, D., Roncoletta, A., \& Moreto, G. (2005). Cinema para o Estudante de Medicina: um Recurso Afetivo/Efetivo na Educação Humanística. Revista Brasileira de Educação Médica, 29(2), 119-128.

Blasco, P. G. (2010). É possível humanizar a Medicina? Reflexões a propósito do uso do Cinema na Educação Médica. O Mundo da Saúde, 34 (3), 357-367.

Brasil (2002). Lei n ${ }^{\circ}$ 10.436, de 24 abril de 2002. Dispõe sobre a Língua Brasileira de Sinais - Libras e dá outras providências. Diário Oficial da União, Brasília, DF.

Brasil (2014). Resolução n 3, de 20 de junho de 2014. Institui Diretrizes Curriculares Nacionais do Curso de Graduação em Medicina e dá outras providência. Diário Oficial da União, Brasília, DF.

Brescia, V. P. (2003). Educação Musical: bases psicológicas e ação preventiva. Átomo.

Casanova, I. A., Batista, N., \& Moreno, L. (2018). A Educação Interprofissional e a prática compartilhada em programas de residência multiprofissional em Saúde. Interface: comunicação, saúde e educação, 22 (1), 1325-1337.

Coutinho, C., \& Lisbôa, E. (2011). Sociedade da informação, do conhecimento e da aprendizagem: desafios para educação no século XXI. Revista de Educação, 18(1), 5-22.

Cruz, C., \& Riera, R. (2016). Comunicando más notícias: o protocolo SPIKES / Acupuncture treatment of obesity. Diagnóstico e tratamento, 21(3), 106-108.

Ferreira, T., \& Queiroz, G. (2021). A música como recurso metodológico para o ensino da Libras como segunda língua para ouvintes. Revista Científica Eletrônica de Ciências Aplicadas da FAIT, 1, 1-15.

Fialho, D. M. (2006). Arte e Cartografia. Fonte: Arte e Cidade: http://www.arteecidade.ufba.br/st3_DMF.pdf

Filho, J. M. (2003). Relacionamento médico-paciente. Revista Brasileira de Reumatologia, 43(4), 238-239.

Fiuza, W. M., \& Lhullier, C. (2018). Possíveis Aplicações da Técnica de Role-Play no Atendimento a Famílias Adotantes. Pensando Famílias, 22 (2), 20-36.

Franco, C., Cubas, M., \& Franco, R. (2014). Currículo de medicina e as competências propostas pelas diretrizes curriculares. Revista Brasileira de Educação Médica, 38(2), 221-230.

Franco, T. B., \& Merhy, E. (2012). Cartografias do Trabalho e Cuidado em Saúde. Revista Tempus Actas de Saúde Coletiva, 6 (2), $151-163$.

Frasson, F. (2016). Aprendizagem significativa conceitual, procedimental e atitudinal na educação alimentar e nutricional, no ensino fundamental, por meio de multiplicidade representacional. Biblioteca Digital Brasileira de Teses e Dissertações.

Freire, P. (1997). Educação bancária e educação libertadora. São Paulo: Casa do Psicólogo.

Hatem, T., Lira, P., \& Mattos, S. (2006). The therapeutic effects of music in children following cardiac surgery. Jornal de pediatria, 82 (3), $186-192$. 
Honorato, T. G., Mazzaia, M. C., Avezani, A. C., \& Neto, F. L. (2021). Cinema brasileiro e o ensino dos transtornos da personalidade. Revista Brasileira de Educação Médica, 45(2),1-7.

Hwang, I. C., Park, K. H., Kim, J. J., Yim, J., Ko, K. P., Bae, S. M., \& Kyung, S. Y. (2017). Perceived Social Support as a Determinant of Quality of Life Among Medical Students: 6-Month Follow-up Study. the journal of the American Association of Directors of Psychiatric Residency Training and the Association for Academic Psychiatry, 41(2), 180-184.

Knapp, P., \& Beck, A. T. (2018). Fundamentos, modelos conceituais, aplicações e pesquisa da terapia cognitiva. Revista Brasileira de Psiquiatria, 30(2), 5464.

Larosa, J. B. (2002). Notas sobre a experiência e o saber de experiência. Revista Brasileira de Educação, 19, 20-27.

Larosa, J. B. (2011). Experiência e alteridade em educação. Revista Reflexão e Ação, 19(2), 04-27.

Lino, C. A., Augusto, K. L., Oliveira, R. A., Feitosa, L. B., \& Caprara, A. (2011). Uso do protocolo Spikes no ensino de habilidades em transmissão de más notícias. Revista Brasileira de Educação Médica, 35(1), 52-57.

Lorenz, K., Steckart, M., \& Rosenfeld, K. (2004). End-of-Life Education Using the Dramatic Arts: The Wit Educational Initiative. Academic Medicine, 79(5), 481-486.

Loureiro, A. M. A. (2001). O Ensino da Música na Escola Fundamental: Um Estudo Exploratório. Dissertação de mestrado, Pontifícia Universidade Católica de Minas Gerais, Belo Horizonte, MG Brasil.

Machado, A. M., Gõttems, L. B. D., Pires, M. R. G. M. (2013). Aprendizagem em saúde mental por meio da produção videográfica: relato de experiência. Texto Contexto Enferm, 22(4), 1205-1213.

Melendéz, A. Z. (2012). Los contenidos procedimentales en el proceso de enseñanza-aprendizaje. Tese de doutorado, Universidad de Granada, Granada, Espanha. https://digibug.ugr.es/bitstream/handle/10481/23766/21224225.pdf?sequence=1\&isAllowed=y .

Ministério da Educação. (2020). INEP. Fonte: Instituto Nacional de Estudos e Pesquisas Educacionais Anísio Teixeira: https://download.inep.gov.br/educacao_superior/revalida/portaria/2020/Portaria_540_17092020.pdf

Mongelli, M. S., Ferrante, M., \& Arcas, P. H. (2021). The use of the mock trial as an active methodology in Vet. Research, Society and Development, 10(12), e06101219866.

Mourão, M. d., Caldeira, A. P., \& Raposo, J. J. (2009). A avaliação no contexto da formação médica. Revista Brasileira de Educação Médica, 33 (3), $452-464$.

Paro, H. B., Perotta, B., Enns, S. C., Gannam, S., Giaxa, R. R., Arantes-Costa, F. M., Tempski, P. Z. (2019). Qualidade de vida do estudante de medicina: o ambiente educacional importa? Rev Med (São Paulo), 98 (2), 140-147.

Picanço, T. S. C., Nazima, M. T. S. T., Santos, B. E. F., Júnior, O. M. P., Cambraia, M. I. A., Morais, L. S. S., Pena, L. F. S., Costa, K. S. N. (2019). Revista Brasileira de Educação Médica, 43(1); 57-68.

Resolução CFM nº 2.217, de 27 de setembro de 2018 (2018). Aprova o Código de Ética Médica. Conselho Federal de Medicina, Brasília, DF.

Rotenstein, L. S., Ramos, M. A., Torre, M., Segal, J. B., Peluso, M. J., Guille, C., . . Mata, D. A. (2016). Prevalence of depression, depressive symptoms, and suicidal ideation among medical students: a systematic review and meta-analysis. JAMA, 316 (21), 2214-2236.

Silva, A. N., Senna, M. A., Teixeira, M. C., Lucietto, D. A., \& Andrade, I. M. (2020). O uso de metodologia ativa no campo das Ciências Sociais em Saúde: relato de experiência de produção audiovisual por estudantes. Interface - Comunicação, Saúde, Educação, 24: e190231, 1-14.

Silva, M. de L., Silva, M. P. B., Leite, A. C., Melo, B. C., Santos, A. B. A. de S.., Moura, L. C. de, Sobrinho, W. D., Santos, A. G. dos, Moraes, R. dos S., Araujo, G. B., Amorim, A. P., Apolinário, J. M. dos S. da S., \& Fagundes, G. R. S. (2021). As dificuldades encontradas na assistência à saúde às pessoas com surdez. Research, Society and Development, 10(2), e38910212372.

Silva, R. H. A; Scapin L. T; Batista N. A. Evaluation of interprofessional education in undergraduate health science: aspects of collaboration and teamwork. Avaliação, 16(1), 167-184.

Silva, S. R., Silveira, L. G., Fraga, L. d., \& Gomes, O. V. (2019). A dramatização como estratégia de ensino-aprendizagem na perspectiva discente: um relato de experiência no curso de medicina. Revista De Medicina, 98(5), 324-328.

Silveira, H. M., \& Jayme, N. S. (2014). Cartografia de síntese e geografia da saúde: aproximações teóricas. Bol. geogr., 32 (3), $122-137$. 